\title{
SELEÇÃO DE ÍNDICES NA ANÁLISE DE BALANÇOS: UMA APLICAÇÃO DA TÉCNICA ESTATÍSTICA 'ACP'
}

\author{
SELECTION OF INDEXES FOR FINANCIAL STATEMENT ANALYSIS: \\ AN USE OF THE STATISTIC METHODOLOGY 'AMC'
}

\author{
JOÃO FRANCISCO MOROZINI \\ Professor e Pesquisador Mestre em Ciências \\ Contábeis do Centro de Ciências Sociais \\ Aplicadas da Universidade Estadual do Centro \\ Oeste - PR \\ E-mail: jmorozini@unicentro.br
}

\section{JOSÉ LEONIDAS OLINQUEVITCH}

Professor Doutor do Centro de Ciências Sociais

Aplicadas e do Programa de Pós-Graduação em

Ciências Contábeis da Universidade Regional de

Blumenau - SC

E-mail: olinquevitch@furb.br

\section{RESUMO}

Este trabalho objetiva examinar a situação econômico-financeira de sociedades anônimas em processo de concordata, a fim de ressaltar a possibilidade de a análise das demonstrações contábeis evidenciar um parâmetro para identificação de processo de concordata. Utiliza pesquisa descritiva, com abordagem quantitativa, e análise documental. Foram identificados 99 processos de empresas em concordata, protocolados nas Varas da Fazenda Pública de Curitiba/PR, mas o estudo está delimitado às empresas constituídas sob forma de sociedade anônima, com porte classificado como middle pela SERASA, num total de 10 empresas. Após realizar a análise das demonstrações contábeis dessas empresas, foi possível dar tratamento estatístico aos dados. A estatística aplicada, neste estudo, foi a Análise das Componentes Principais (ACP), utilizando-se do software Matlab (Matrix Laboratory). Essa metodologia foi aplicada nas 10 empresas observadas, com as 12 variáveis, que correspondem ao grupo de índices selecionados para a análise das demonstrações contábeis. Os resultados da pes-

\author{
NELSON HEIN \\ Professor Doutor do Centro de Ciências Exatas \\ e Naturais e do Programa de Pós-Graduação em \\ Ciências Contábeis da Universidade Regional de \\ Blumenau - SC \\ E-mail: hein@furb.br
}

\begin{abstract}
This paper aims at accomplishing an economic-financial analysis of corporations in process of receivership, emphasizing the possibility of a financial statement analysis being able to serve as a parameter to identify the business failure process. It uses a descriptive research, with quantitative approach and documental analysis. Ninety-nine processes of corporations in receivership are registered on the applicable civil courts of the city of Curitiba, in the State of Paraná, but the study is restricted to corporations, classified as middle sized by SERASA (a database center), in a total of 10 companies. The methodology adopted has been the "Analysis of the Main Components (AMC)", utilizing the Matlab (Matrix Laboratory) software. This methodology was applied on the 10 companies observed on this study, with the 12 variables corresponding to the selected group of indexes for the analysis of financial statements. The results of the research show which are the main indexes, among the selected ones, with relevance on the analysis of financial statements, to detect the tendency of insolvency. It has been concluded that,
\end{abstract}


quisa evidenciam os principais índices entre os selecionados para o estudo, com maior relevância na análise das demonstrações, para verificar tendência de insolvência. Concluiu-se que, dos 12 índices estudados nesta pesquisa, 5 evidenciam tendência para insolvência.

Palavras-chave: Análise Econômico-financeira; Processo de Concordata; Sociedades Anônimas. within this research, 5 out of 12 indexes studied are relevant to show a tendency to insolvency.

Keywords: Economic-financial analysis; Receivership (Creditors' Agreement Process); Corporations.

\section{INTRODUÇÃO}

Este trabalho busca verificar, por meio da análise das demonstrações contábeis se a aplicação de uma seleção de índices pode ajudar a identificar, prováveis direcionadores para problemas econômicos e financeiros. Para isso, será utilizada, como auxílio, a estatística aplicada: neste trabalho específico, a Análise das Componentes Principais "ACP". Este estudo foi desenvolvido em empresas Sociedades Anônimas em processo de Concordata, antes da promulgação da Lei 11.101 de 9 de fevereiro de 2005 que regula a recuperação judicial, a extrajudicial e a falência de empresário e da sociedade empresária.

Considerando a evidenciação das demonstrações contábeis das sociedades anônimas, formulou-se o seguinte problema de pesquisa: Após uma seleção de índices para se fazer análise nas demonstrações contábeis de empresas constituídas sob forma de sociedade anônima e em processo de concordata, é possível identificar quais índices podem ter maior ou menor relevância na análise, utilizando-se para isso um método estatístico?

Para se iniciar o processo de análise das demonstrações contábeis, Mintzberg (1988); Brigham, Gapenski e Ehrhardt (2001) afirmam que geralmente se começa com cálculo de um conjunto de índices econômico-financeiros desenvolvidos para revelar os pontos fortes e fracos das empresas. Acrescenta Garrison e Norren (2001) que "os índices não devem ser considerados um fim, mas sim um ponto de partida".

Para este estudo foram selecionados os índices que compõem a situação financeira, a situação econômica, a estrutura de capitais e o capital de giro. A justificativa para a escolha desses índices é o fato de as análises das demonstrações contábeis, normalmente, apresentarem esses grupos de índices, sendo utilizados tanto do ponto de vista de investidores, credores, gestores, e também utilizados por pesquisadores, analistas e consultores da área contábil-financeira.

Logo após a introdução, o artigo está estruturado da seguinte forma: na segunda seção, é apresen- tado o referencial teórico que fundamenta o estudo; a terceira seção refere-se à metodologia utilizada no desenvolvimento da pesquisa; na quarta seção, são apresentados a discussão e os resultados e a quinta seção mostra, finalmente, as considerações finais deste artigo.

\section{REFERENCIAL TEÓRICO}

As informações são obtidas dos dados contábeis e um dos meios, para se obterem tais informações, é a análise das demonstrações contábeis.

Estudos indicam que os primeiros modelos de análise de balanços foram realizados por meio de índices e demonstrou a necessidade de se considerarem outras relações, além do confronto do ativo circulante e o passivo circulante segundo Alexander Wall (1919 apud MATARAZZO, 1985), considerado o pai da análise de balanços. A partir daí, inúmeras fórmulas, relações, índices, são acrescentados a esse estudo descrito sob o ponto de vista financeiro por Bodie e Merton (1998); ludícibus (1998); ainda por Ross, Westerfield e Jaffe (2002). Estudos relacionados à análise das demonstrações contábeis demonstram como objetivo de antecipar condições futuras, conforme Weston e Brigham (2000); Matarazzo (2003); Olinquevitch e Santi Filho (2004), transformando a análise das demonstrações contábeis em uma das áreas bastante pesquisadas na Ciência Social Aplicada. Apresenta-se uma discussão sobre os índices que foram aplicados na análise econômico-financeira das demonstrações contábeis das empresas concordatárias desse estudo.

Para se chegar à discriminação dos dados, utilizaram-se os seguintes índices para fazer a análise das demonstrações contábeis, conforme Wright, Kroll e Parnell (2000); Helfert (2000); ludícibus (1998); Marion (2002); Gitman e Madura (2003); Schrickel (1999) e Olinquevitch e Santi Filho (2004):

I Situação Financeira: Índice de Liquidez Geral, Liquidez Corrente e Liquidez Seca;

II Situação Econômica: Índice de Giro do Ativo, Rentabilidade do Ativo e Rentabilidade do Patrimônio Líquido; 
III Estrutura de Capitais: Índice de Participação de Capitais de Terceiros, Composição do Endividamento e Imobilização do Patrimônio Líquido;

IV Análise Financeira Avançada: Capital Circulante Líquido, Capital de Giro e a Necessidade Líquida de Capital de Giro.

Na concepção de ludícibus (1998); Silva (2001) e Matarazzo (2003), o índice de liquidez geral tem como objetivo evidenciar de forma quantitativa a representatividade do ativo circulante somado com o realizável a longo prazo em relação ao passivo diminuído de seu patrimônio líquido. Esse índice demonstra a capacidade de pagamento total das dívidas, representadas pelo curto e longo prazo.

$O$ índice mais utilizado para avaliar a exposição à divida representada no balanço patrimonial é o índice de liquidez corrente, segundo Helfert (2000) e Silva (2001). Ele relaciona os ativos circulantes com os passivos circulantes e é uma tentativa de demonstrar a segurança dos direitos dos possuidores da dívida atual no caso de inadimplência.

Sobre o índice de liquidez seca, Weston e Brigham (2000); Marion (2002) e Silva (2001) expõem que é o somatório das disponibilidades, mais aplicações financeiras, mais duplicatas a receber, dividindo-se o total pelo passivo circulante, para indicar quanto a empresa possui em disponibilidades. O conceito-chave, aqui, é testar a capacidade de pagar os passivos circulantes no caso de uma crise real, na suposição de que os estoques não teriam nenhum valor. (HELFERT, 2000).

Quanto aos índices de rentabilidade, Padoveze (2003); Santos (2000); Gitman e Madura (2003) e ludícibus (1998) afirmam que uma rentabilidade adequada continuamente é, possivelmente, o maior indicador da sobrevivência e sucesso de uma empresa. Assim, o índice de giro do ativo é considerado um importante indicador que mede a situação operacional da empresa, fazendo relação das vendas de um determinado período com os investimentos efetuados na empresa no mesmo período.

O índice de rentabilidade do ativo, para Silva (2001); Matarazzo (2003) e Helfert (2000) tem como finalidade indicar de forma quantitativa a lucratividade que a empresa consegue gerar com determinado ativo, ou seja, qual a quantidade de lucro que o total dos investimentos em ativo propicia para a empresa. Gitman e Madura (2003, p.202) tratam o índice de rentabilidade do ativo, com a nomenclatura de Retorno sobre o Ativo Total (ROA - Return On Total Assets), para medir a eficiência geral da administração em gerar lucros com seus ativos disponíveis.
Weston e Brigham (2000); Helfert (2000) Ross, Westerfiel e Jaffe (2002) afirmam que o índice de rentabilidade do patrimônio líquido objetiva medir o retorno do capital investido no empreendimento, também denominado de ROE (Return On Common Equity).

Os índices que tratam da estrutura de capital são significativos para a análise das demonstrações contábeis, pois retratam a situação do endividamento, relacionando o capital próprio com o capital de terceiros, evidenciando a dependência financeira da empresa com terceiros. (DAMODARAN, 2002 e ASSAF NETO,2003). O objetivo do índice de participação de capitais de terceiros, segundo ludícibus (1998); Weston e Brigham (2000) e Matarazzo (2003) é demonstrar qual é a dependência financeira da empresa, em relação à utilização de capital de terceiros e o capital próprio, indicando, assim, a proporção de quanto a empresa possui de dívidas confrontadas com o capital próprio.

O índice de composição do endividamento evidencia as dívidas de curto prazo e, conforme ludícibus (1998), algumas precauções precisam ser tomadas pelos gestores, quanto ao endividamento relacionado com investimentos em empresas, visando ao crescimento. Deve-se evitar financiar expansão com empréstimo de curto prazo, a não ser que o período de Payback dos ativos seja curtíssimo, fato que raramente ocorre, segundo ludícibus (1998).

Silva (2003) e Matarazzo (2003) afirmam que o índice de imobilização do patrimônio líquido indica quanto do patrimônio líquido da empresa está aplicado no ativo permanente. É importante destacar que o índice de imobilização do patrimônio líquido está ligado diretamente com as decisões estratégicas da empresa.

Olinquevitch e Santi Filho (2004) expõem que, sob a óptica da análise financeira tradicional, o capital circulante líquido é largamente utilizado com abordagem financeira, por fornecer uma visão dos aspectos financeiros de curto prazo. Groppelli e Nikbakht (1999); Assaf Neto (2002) e Silva (2003) salientam que o conceito de capital circulante líquido se apresenta mais claramente identificado como o excedente das aplicações a curto prazo e pode, também, ser pensado como a porção dos ativos circulantes que deve ser financiada pelo longo prazo.

Conforme Houston e Brigham (1999); Assaf Neto (2002) e Olinquevitch e Santi filho (2004), a política de capital de giro se refere às decisões da empresa com respeito a níveis desejados de cada categoria de ativos correntes e como os ativos circulantes serão financiados. Na concepção de Schrickel (1999), capital de giro é o montante de recursos que não está imobilizado. 
O índice de necessidade líquida de capital de giro, conforme Marion (2002); Assaf Neto (2002) e Olinquevitch e Santi Filho (2004), constitui-se como determinante da situação financeira das empresas. Seu valor revela o nível de recursos necessários para manter o giro dos negócios.

É necessário estar atento para a análise das demonstrações contábeis, que deve ser tratada com cuidado, pois não existe um roteiro padronizado.

Os limites e desafios da análise das demonstrações contábeis sempre são objeto de estudos e pesquisas. Faz-se necessária a compreensão da função e do objetivo da análise dentro da gestão empresarial, em que esse instrumento deve gerar informações comprometidas com a continuidade e com o desenvolvimento sustentável dos negócios.

\section{METODOLOGIA DA PESQUISA}

A pesquisa sobre as empresas constituídas sob a forma de sociedade anônima em processo de concordata teve como etapas preliminares:

a) levantamento de dados junto à SERASA da quantidade de empresas que, durante os últimos três anos, entraram em processo de concordata, mês a mês, em todo o Brasil; b) utilização de dados da SERASA, para delimitação do trabalho;

c) levantamento das bibliografias que fundamentam esta pesquisa;

d) definição do local e da forma de coleta dos dados a serem estudados, os quais serão detalhados em tópicos específicos;

e) determinação da forma de exposição do resultado da pesquisa, visto que a análise dos dados foi quantitativa.

A classificação desta pesquisa é descritiva quanto ao objetivo geral e aos específicos; documental quanto aos procedimentos; e quanto à abordagem do problema, teve tratamento quantitativo.

\subsection{População em estudo}

Optou-se pela realização da pesquisa nas empresas constituídas sob a forma de sociedades anônimas na cidade de Curitiba/PR, segundo critérios da SERASA, as quais, pela sua estrutura, atendem aos requisitos de credibilidade quanto às demonstrações contábeis, conforme classificação do porte das empresas mostrada na Tabela 1, a seguir:

Tabela 1 - Classificação do porte das sociedades anônimas
\begin{tabular}{l|l|r}
\hline Porte da Empresa & & Faturamento \\
\hline Corporate & maior que & $\mathrm{R} \$ 50.000 .000,00$ \\
\hline Middle & menor ou igual a & $\mathrm{R} \$ 50.000 .000,00$ \\
\hline Small & menor ou igual a & $\mathrm{R} \$ 250.000,00$ \\
\hline
\end{tabular}

Fonte: Relatório estatístico da SERASA em 2004.

Para delimitar esta pesquisa, foram utilizadas somente as empresas constituídas sob a forma de Sociedade Anônima em processo de concordata e classificadas como middle e corporate, ou seja, empresas com faturamento na escala de
$R \$ 250.000,00$ a $R \$ 50.000 .000,00$ classificadas como midle e empresas com faturamento acima de $R \$ 50.000 .000,00$ classificadas como corporate, com base na Tabela 1 .

Tabela 2 - Identificação das empresas concordatárias

\begin{tabular}{l|c|c|c|c}
\hline Forma de Constituição & 1. $^{\text {a }}$ Vara & 2. $^{\text {a }}$ Vara & 3. $^{\text {a }}$ Vara & 4. $^{\text {a }}$ Vara \\
\hline Sociedade Limitada & 21 & 13 & 28 & 23 \\
\hline Sociedade Anônima & 1 & 3 & 2 & 4 \\
\hline Firma Individual & 2 & 2 & 0 & 0 \\
\hline Total & $\mathbf{2 4}$ & $\mathbf{1 8}$ & $\mathbf{3 0}$ & $\mathbf{2 7}$
\end{tabular}

Fonte: $1^{\text {a }} 2^{2}$. $3^{\text {a }}$. e $4^{\text {a }}$. Varas dos Cartórios da Fazenda Pública de Curitiba-PR 
Para compor a população deste estudo, buscou-se, entre a totalidade das empresas concordatárias no Brasil, quantas são da cidade de Curitiba/ PR e que estão com processos protocolados nos Cartórios das Varas da Fazenda Pública de Curitiba/PR, constituídas pela primeira, segunda, terceira e quarta Varas, as quais estão evidenciadas de acordo com a forma de constituição na Tabela 2. A leitura das empresas concordatárias foi realizada no período de maio a outubro de 2004.

Conforme a Tabela 2, foram identificadas 99 empresas em processo de concordata, protocoladas nas Varas da Fazenda Pública de Curitiba/PR. Com base na delimitação dessa pesquisa, foram selecionadas para comporem a população dessa pesquisa todas as empresas constituídas sob a forma de sociedade anônima, em processo de concordata. Assim sendo, a população deste estudo compõe-se de 10 empresas, constituídas sob a forma de sociedade anônima em processo de concordata, em que todas são classificadas como middle pela SERASA. Essa constatação se deu após a verificação dos balanços e das demonstrações de resultados das empresas objeto de estudo.

\subsection{Coleta dos dados}

Os instrumentos de coleta de dados utilizados em pesquisa são: a entrevista, o formulário, a pesquisa documental e o questionário, os quais são considerados como procedimentos técnicos ou meios para realizar a pesquisa.

Para este estudo, tratando-se de uma pesquisa descritiva, o método de coleta de dados utilizado foi a pesquisa documental.

Segundo Gil (2002, p.45), existe uma diferença entre pesquisa documental e bibliográfica, conforme descrito a seguir: "A diferença essencial entre ambas está na natureza das fontes. Enquanto a pesquisa bibliográfica se utiliza fundamentalmente das contribuições dos diversos autores sobre determinado assunto, a pesquisa documental vale-se de materiais que não receberam ainda tratamento analítico, ou que ainda podem ser reelaborados de acordo com os objetivos da pesquisa."
Os dados coletados são de natureza quantitativa, concentrando-se nas demonstrações contábeis dos anos de 2001, 2002 e 2003 das empresas em estudo. Esses processos são de conhecimento e acesso público; assim, foram solicitados, junto às Varas da Fazenda Pública de Curitiba/PR, os três últimos balanços e demonstrações de resultados dessas empresas.

\subsection{Tratamento estatístico dos dados}

Para realizar a análise dos dados deste estudo, buscou-se fazer análise das demonstrações contábeis dos anos de 2001, 2002 e 2003 das empresas que compõem a população em estudo. Os índices extraídos da análise das demonstrações contábeis receberam tratamento estatístico de Análise das Componentes Principais (ACP), utilizando-se o software Matlab (Matrix Laboratory).

A análise das componentes principais é uma forma de transformar as variáveis originais em componentes principais, ou seja, é uma técnica de transformação de variáveis, em que por ocasião do resultado da pesquisa, é investigado se todas as variáveis contribuíram para explicar a variabilidade total dos dados.

A estatística aplicada refere-se às técnicas de análise nas quais o ponto central é a tomada de decisão sob condições de incertezas, Kazmier (1982).

\section{DISCUSSÃO E APRESENTAÇÃO DOS RESULTADOS}

Após a coleta dos dados procedeu-se à análise, discussão e apresentação dos resultados, buscando garantir a sua precisão, evitar distorções de análise, discussão e interpretação, possibilitando, conseqüentemente, uma margem de segurança quanto às influências. (RICHARDSON,1989).

Com a realização deste estudo, puderam ser levantados os dados extraídos das demonstrações contábeis das empresas concordatárias, de acordo com os índices definidos no referencial teórico, conforme as Figuras 1, 2 e 3, construídas a seguir:

\begin{tabular}{|c|c|c|c|c|c|c|c|c|c|c|c|c|}
\hline \multirow{2}{*}{$\frac{\stackrel{\varrho}{E}}{\text { ய் }}$} & \multicolumn{3}{|c|}{ Liquidez } & \multicolumn{3}{|c|}{ Lucratividade } & \multicolumn{3}{|c|}{ Estrutura de Capitais } & \multicolumn{3}{|c|}{ Capital de Giro } \\
\hline & $\begin{array}{l}\text { Liq. } \\
\text { Geral }\end{array}$ & $\begin{array}{l}\text { Liq. } \\
\text { Cor. }\end{array}$ & $\begin{array}{l}\text { Liq. } \\
\text { Seca }\end{array}$ & $\begin{array}{l}\text { Giro } \\
\text { Ativo }\end{array}$ & $\begin{array}{c}\text { Rentab. } \\
\text { Ativos }\end{array}$ & $\begin{array}{c}\text { Rentab. } \\
\text { PL }\end{array}$ & $\begin{array}{l}\text { Endiv. } \\
\text { Cap. 3. }\end{array}$ & $\begin{array}{l}\text { Comp. } \\
\text { Exigib. }\end{array}$ & $\begin{array}{c}\text { Imobil. } \\
\text { PL }\end{array}$ & CCL & CDG & NLCG \\
\hline$A$ & 1,12 & 0,75 & 0,10 & 0,94 & $-0,45 \%$ & $-1,47 \%$ & $93,88 \%$ & $44,13 \%$ & $95,10 \%$ & $0,60 \%$ & $29,90 \%$ & $2,11 \%$ \\
\hline B & 5,51 & 5,40 & 4,39 & 0,36 & $0,42 \%$ & $2,00 \%$ & $272,68 \%$ & $23,58 \%$ & $18,14 \%$ & $75,88 \%$ & $93,13 \%$ & $-4,28 \%$ \\
\hline C & 4,16 & 2,57 & 0,12 & 0,79 & $11,61 \%$ & $15,30 \%$ & $31,81 \%$ & $81,03 \%$ & $24,54 \%$ & $30,78 \%$ & $50,34 \%$ & $42,65 \%$ \\
\hline
\end{tabular}


Continuação

\begin{tabular}{|c|c|c|c|c|c|c|c|c|c|c|c|c|}
\hline \multirow{2}{*}{ 를 } & \multicolumn{3}{|c|}{ Liquidez } & \multicolumn{3}{|c|}{ Lucratividade } & \multicolumn{3}{|c|}{ Estrutura de Capitais } & \multicolumn{3}{|c|}{ Capital de Giro } \\
\hline & $\begin{array}{l}\text { Liq. } \\
\text { Geral }\end{array}$ & $\begin{array}{l}\text { Liq. } \\
\text { Cor. }\end{array}$ & $\begin{array}{l}\text { Liq. } \\
\text { Seca }\end{array}$ & $\begin{array}{c}\text { Giro } \\
\text { Ativo }\end{array}$ & $\begin{array}{c}\text { Rentab. } \\
\text { Ativos }\end{array}$ & $\begin{array}{c}\text { Rentab. } \\
\text { PL }\end{array}$ & $\begin{array}{l}\text { Endiv. } \\
\text { Cap. } \text { 3. }^{\circ}\end{array}$ & $\begin{array}{l}\text { Comp. } \\
\text { Exigib. }\end{array}$ & $\begin{array}{c}\text { Imobil. } \\
\text { PL }\end{array}$ & CCL & CDG & NLCG \\
\hline D & 1,28 & 1,23 & 0,13 & 2,48 & $-22,52 \%$ & $-68,41 \%$ & $203,75 \%$ & $70,61 \%$ & $120,07 \%$ & $10,94 \%$ & $58,31 \%$ & $7,51 \%$ \\
\hline$E$ & 1,16 & 1,16 & 0,04 & 1,54 & $-12,93 \%$ & $-103,66 \%$ & $701,49 \%$ & $84,68 \%$ & $114,03 \%$ & $11,62 \%$ & $85,74 \%$ & $4,12 \%$ \\
\hline $\mathrm{F}$ & 0,13 & 0,14 & 0,01 & 4,89 & $-26,40 \%$ & $-4,71 \%$ & $-117,82 \%$ & $68,25 \%$ & $-2,55 \%$ & $-385,94 \%$ & $65,26 \%$ & $-391,38 \%$ \\
\hline G & 0,51 & 0,51 & 0,14 & 2,86 & $1,66 \%$ & $25,68 \%$ & $1451,24 \%$ & $88,57 \%$ & $899,54 \%$ & $-40,85 \%$ & $42,01 \%$ & $-44,24 \%$ \\
\hline $\mathrm{H}$ & 0,46 & 0,47 & 0,01 & 0,90 & $-8,95 \%$ & $-19,75 \%$ & $120,55 \%$ & $93,31 \%$ & $165,18 \%$ & $-26,85 \%$ & $24,15 \%$ & $-24,60 \%$ \\
\hline 1 & 2,53 & 2,46 & 0,01 & 1,57 & $-4,32 \%$ & $-5,64 \%$ & $30,61 \%$ & $100,00 \%$ & $53,29 \%$ & $35,76 \%$ & $59,20 \%$ & $35,69 \%$ \\
\hline $\mathrm{J}$ & 1,10 & 1,19 & 0,21 & 2,19 & $15,20 \%$ & $31,40 \%$ & $106,55 \%$ & $52,10 \%$ & $89,39 \%$ & $5,14 \%$ & $32,02 \%$ & $5,93 \%$ \\
\hline
\end{tabular}

Fonte: Elaborada pelos autores.

Figura 1 - Índices obtidos da análise das demonstrações contábeis de 2001

\begin{tabular}{|c|c|c|c|c|c|c|c|c|c|c|c|c|}
\hline \multirow{2}{*}{$\frac{\grave{2}}{\text { ய் }}$} & \multicolumn{3}{|c|}{ Liquidez } & \multicolumn{3}{|c|}{ Lucratividade } & \multicolumn{3}{|c|}{ Estrutura de Capitais } & \multicolumn{3}{|c|}{ Capital de Giro } \\
\hline & $\begin{array}{l}\text { Liq. } \\
\text { Geral }\end{array}$ & $\begin{array}{l}\text { Liq. } \\
\text { Cor. }\end{array}$ & $\begin{array}{l}\text { Liq. } \\
\text { Seca }\end{array}$ & $\begin{array}{l}\text { Giro } \\
\text { Ativo }\end{array}$ & $\begin{array}{c}\text { Rentab. } \\
\text { Ativos }\end{array}$ & $\begin{array}{c}\text { Rentab. } \\
\text { PL }\end{array}$ & $\begin{array}{l}\text { Endiv. } \\
\text { Cap. } 3 .^{\circ}\end{array}$ & $\begin{array}{l}\text { Comp. } \\
\text { Exigib. }\end{array}$ & $\begin{array}{c}\text { Imobil. } \\
\text { PL }\end{array}$ & CCL & CDG & NLCG \\
\hline A & 1,09 & 0,64 & 0,10 & 0,99 & $-4,00 \%$ & $-13,53 \%$ & $97,77 \%$ & $48,97 \%$ & $95,46 \%$ & $-0,35 \%$ & $34,26 \%$ & $1,42 \%$ \\
\hline $\mathrm{B}$ & 5,82 & 5,71 & 4,47 & 0,35 & $0,20 \%$ & $0,82 \%$ & $304,55 \%$ & $21,84 \%$ & $17,25 \%$ & $77,44 \%$ & $93,88 \%$ & $-1,03 \%$ \\
\hline C & 4,98 & 3,10 & 0,36 & 0,78 & $7,59 \%$ & $11,19 \%$ & $47,45 \%$ & $57,78 \%$ & $11,01 \%$ & $39,28 \%$ & $57,88 \%$ & $36,29 \%$ \\
\hline $\mathrm{D}$ & 0,97 & 0,91 & 0,07 & 1,88 & $-24,17 \%$ & $-362,75 \%$ & $-1600,00 \%$ & $66,78 \%$ & $-460,34 \%$ & $-6,67 \%$ & $64,57 \%$ & $4,73 \%$ \\
\hline$E$ & 1,07 & 0,87 & 0,05 & 0,24 & $-6,46 \%$ & $-116,31 \%$ & $1699,39 \%$ & $84,63 \%$ & $266,00 \%$ & $5,29 \%$ & $85,22 \%$ & $-9,91 \%$ \\
\hline $\mathrm{F}$ & 0,10 & 0,11 & 0,01 & 4,88 & $-50,07 \%$ & $-6,97 \%$ & $-113,91 \%$ & $73,32 \%$ & $-2,18 \%$ & $-533,93 \%$ & $66,17 \%$ & $-536,73 \%$ \\
\hline $\mathrm{G}$ & 0,48 & 0,48 & 0,13 & 3,03 & $0,59 \%$ & $8,39 \%$ & $1333,80 \%$ & $91,93 \%$ & $850,49 \%$ & $-44,84 \%$ & $40,68 \%$ & $-46,18 \%$ \\
\hline $\mathrm{H}$ & 0,28 & 0,27 & 0,00 & 0,61 & $-28,01 \%$ & $-85,73 \%$ & $206,10 \%$ & $95,57 \%$ & $247,50 \%$ & $-47,07 \%$ & $17,28 \%$ & $-42,82 \%$ \\
\hline$I$ & 2,63 & 2,58 & 0,36 & 1,83 & $9,47 \%$ & $12,56 \%$ & $32,71 \%$ & $100,00 \%$ & $46,59 \%$ & $40,24 \%$ & $64,89 \%$ & $30,04 \%$ \\
\hline J & 0,99 & 1,31 & 0,13 & 2,02 & $-5,54 \%$ & $-14,24 \%$ & $156,84 \%$ & $57,38 \%$ & $101,67 \%$ & $10,94 \%$ & $45,98 \%$ & $7,01 \%$ \\
\hline
\end{tabular}

Fonte: Elaborada pelos autores.

Figura 2 - Índices obtidos da análise das demonstrações contábeis de 2002

\begin{tabular}{|c|c|c|c|c|c|c|c|c|c|c|c|c|}
\hline \multirow{2}{*}{ 远 } & \multicolumn{3}{|c|}{ Liquidez } & \multicolumn{3}{|c|}{ Lucratividade } & \multicolumn{3}{|c|}{ Estrutura de Capitais } & \multicolumn{3}{|c|}{ Capital de Giro } \\
\hline & $\begin{array}{l}\text { Liq. } \\
\text { Geral }\end{array}$ & $\begin{array}{l}\text { Liq. } \\
\text { Cor. }\end{array}$ & $\begin{array}{l}\text { Liq. } \\
\text { Seca }\end{array}$ & $\begin{array}{l}\text { Giro } \\
\text { Ativo }\end{array}$ & $\begin{array}{l}\text { Rentab. } \\
\text { Ativos }\end{array}$ & $\begin{array}{c}\text { Rentab. } \\
\text { PL }\end{array}$ & $\begin{array}{l}\text { Endiv. } \\
\text { Cap. 3. }\end{array}$ & $\begin{array}{l}\text { Comp. } \\
\text { Exigib. }\end{array}$ & $\begin{array}{c}\text { Imobil. } \\
\text { PL }\end{array}$ & CCL & CDG & NLCG \\
\hline A & 1,08 & 0,76 & 0,28 & 0,75 & $-10,04 \%$ & $-54,37 \%$ & $137,54 \%$ & $49,94 \%$ & $94,55 \%$ & $-8,31 \%$ & $32,41 \%$ & $-3,21 \%$ \\
\hline$B$ & 1,71 & 1,71 & 0,81 & 0,33 & $23,00 \%$ & $58,08 \%$ & $145,33 \%$ & $25,36 \%$ & $195,03 \%$ & $8,46 \%$ & $20,45 \%$ & $-1,20 \%$ \\
\hline $\mathrm{C}$ & 6,41 & 3,97 & 0,48 & 0,33 & $1,27 \%$ & $2,04 \%$ & $60,91 \%$ & $39,14 \%$ & $8,15 \%$ & $44,08 \%$ & $58,89 \%$ & $38,43 \%$ \\
\hline D & 0,46 & 0,44 & 0,00 & 0,26 & $-24,85 \%$ & $-80,50 \%$ & $223,88 \%$ & $74,63 \%$ & $246,58 \%$ & $-28,98 \%$ & $22,61 \%$ & $-21,90 \%$ \\
\hline E & 1,12 & 0,90 & 0,04 & 0,52 & $-8,20 \%$ & $-90,26 \%$ & $1001,21 \%$ & $84,09 \%$ & $161,00 \%$ & $8,92 \%$ & $85,38 \%$ & $8,92 \%$ \\
\hline $\mathrm{F}$ & 0,03 & 0,01 & 0,00 & 6,92 & $-36,56 \%$ & $-11,87 \%$ & $-103,63 \%$ & $74,56 \%$ & $-0,42 \%$ & $-297,67 \%$ & $27,55 \%$ & $-290,37 \%$ \\
\hline$G$ & 0,42 & 0,42 & 0,11 & 3,29 & $2,71 \%$ & $49,28 \%$ & $1718,26 \%$ & $97,00 \%$ & $1113,30 \%$ & $-52,90 \%$ & $-38,77 \%$ & $-52,54 \%$ \\
\hline $\mathrm{H}$ & 0,25 & 0,24 & 0,00 & 0,11 & $-4,88 \%$ & $-17,28 \%$ & $254,07 \%$ & $94,13 \%$ & $289,56 \%$ & $-51,26 \%$ & $16,29 \%$ & $-47,54 \%$ \\
\hline I & 0,71 & 0,84 & 0,00 & 0,75 & $-51,38 \%$ & $-252,68 \%$ & $-591,81 \%$ & $100,00 \%$ & $-70,98 \%$ & $-34,77 \%$ & $85,57 \%$ & $-16,72 \%$ \\
\hline $\mathrm{J}$ & 0,86 & 0,90 & 0,03 & 0,19 & $-6,40 \%$ & $-37,21 \%$ & $481,21 \%$ & $88,10 \%$ & $169,37 \%$ & $-7,27 \%$ & $65,68 \%$ & $2,79 \%$ \\
\hline
\end{tabular}

Fonte: Elaborada pelos autores.

Figura 3 - Índices obtidos da análise das demonstrações contábeis de 2003 
Para apurar o resultado da pesquisa, conforme os objetivos previstos neste estudo, e com aplicação da análise das componentes principais (ACP), foi necessário verificar se todas as variáveis contribuíram para explicar a variabilidade total dos dados.

A análise das componentes principais é uma forma de transformar as variáveis originais em componentes principais, ou seja, é uma técnica de transformação de variáveis.

Verificou-se que o estudo envolve 10 empresas, as quais compõem a população, e os índices selecionados para essa pesquisa são 12. As empresas são consideradas como observações e os índices são considerados variáveis.

As identificações das variáveis estudadas nas observações são as seguintes: Variável 1 - Liquidez geral; Variável 2 - Liquidez corrente; Variável 3 - Liquidez seca; Variável 4 - Giro do ativo; Variável 5 - Rentabilidade do ativo; Variável 6 - Rentabilidade do patrimônio líquido; Variável 7 - Participação de capital de terceiros; Variável 8 - Composição das exigibilidades; Variável 9 - Imobilização do patrimônio líquido; Variável 10 - Capital circulante líquido; Variável 11 - Capital de giro; Variável 12 - Necessidade líquida de capital de giro.

O estudo proposto foi realizar a análise das demonstrações contábeis dos anos de 2001, 2002 e 2003 das empresas em processo de concordata. Dessa forma, multiplicando-se a quantidade de empresas concordatárias pelos períodos analisados, passou-se a ter 30 observações com 12 variáveis, correspondentes ao grupo de índice selecionado.

Para investigar as relações entre um conjunto de $p$ variáveis correlacionadas, pode ser útil transformar o conjunto de variáveis originais em um novo conjunto de variáveis não correlacionadas chamadas componentes principais, tendo propriedades especiais em termos de variância.

As novas variáveis componentes principais são combinações lineares das variáveis originais e são derivadas em ordem decrescente de importância, conforme demonstrado na Figura 4.
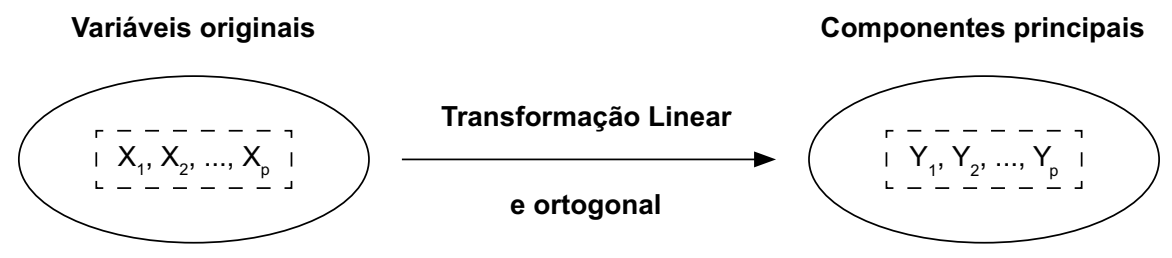

Fonte: Adaptada de Johnson e Wichern (1998)

Figura 4 - Correlação entre variáveis

Segundo Johnson e Wichern (1998), a reprodução da variabilidade total do sistema requer as $p$ variáveis, porém freqüentemente a maior parte dessa variabilidade pode ser explicada por um número pequeno $\mathrm{k}<\mathrm{p}$, de componentes principais.

Nesse caso, existe praticamente a mesma quantidade de informações nas $\mathrm{k}$ componentes principais que nas $p$ variáveis originais. As $k$ componentes principais podem, então, substituir as $p$ variáveis originais.

A finalidade de aplicação da análise de componentes principais é verificar se todas as variáveis contribuem para explicar o sistema. Se for observado que nem todas as variáveis contribuem na explicação do sistema, faz-se necessário descartar tais variáveis independentes com o objetivo de aumentar a precisão das estimativas de regressão com as variáveis retidas e reduzir o número de medidas necessárias em dados semelhantes no futuro.

Uma maneira de descartar variáveis componentes principais é a indicada por Mardía, Kent e Bibby (1979), conforme é visto a seguir: a) determinar os autovalores e autovetores da matriz de correlação das variáveis independentes;

b) considerar o autovetor correspondente ao menor autovalor (valor absoluto), descartar, aí, a variável cujo coeficiente no autovetor for o maior (valor absoluto). O autovetor com menor autovalor é o menos importante no conjunto.

c) O número de variáveis descartadas deve ser igual ao número de autovalores menores ou iguais a 0,70 .

Para se calcular os autovalores e os autovetores, deve-se seguir uma seqüência que é apresentada por Landim (2000, p.41). Se A for uma matriz simétrica de variâncias e covariâncias, com termos $a_{i i j}$, da qual os autovalores e os autovetores serão extraídos, $V_{i}$ o i'ésimo autovetor, cujos termos são $v_{i j}$ e li o i'ésimo autovalor, tal relação pode ser expressa por: 


$$
\left(A-\lambda_{i} I\right) V_{i}=0
$$

em que, I é a matriz de identidade.

Alternativamente, a relação acima pode ser escrita por:

$$
A V_{i}=V_{i} \lambda_{i} \text { ou, }[A][V]=[V][\Lambda],
$$

em que, [V] é uma matriz, $\mathrm{p} \times \mathrm{p}$, de todos os autovetores e $[\Lambda]$ é uma matriz, $p \times p$, com os autovalores $\lambda_{\mathrm{i}}$ na diagonal principal.

Multiplicando-se ambos os lados da equação pela transposta de V, V'.

$$
[A]=[V][\Lambda][V]
$$

A soma dos autovalores é igual à soma dos termos da diagonal em $[A]$, ou seja, a soma das variâncias:

$$
\Sigma \lambda_{i}=\Sigma a_{i i}
$$

e, por definição, $\lambda_{1} \geq \lambda_{2} \ldots \geq \lambda_{p}$.
Resolvendo a equação acima para $\lambda$, as raízes determinadas serão os autovalores. Encontrados os autovalores, substituindo-os nas equações simultâneas e resolvendo-as, obtêm-se para cada autovalor autovetores correspondentes, ou seja, as componentes principais.

Realizou-se a Análise das Componentes Principais nas 30 observações com as 12 variáveis por meio de uma matriz $30 \times 12$ no Software Matlab, cujo objetivo da análise foi verificar se todas as variáveis contribuem para explicar a variabilidade total dos dados.

Com a aplicação da 'ACP' foi possível identificar quais variáveis deveriam ser descartadas por não satisfazerem as condições acima descritas.

Para se chegar às variáveis a serem descartadas, partiu-se dos índices encontrados na análise das demonstrações contábeis, em que foi calculada a matriz covariância e a matriz correlação de cada variável. O resultado dessa operação resultou nos autovalores da matriz covariância de cada variável,

\begin{tabular}{|c|c|c|c|c|c|c|c|c|c|c|c|}
\hline \multicolumn{12}{|c|}{ MATRIZ COVARIÂNCIA } \\
\hline 3.3408 & 2.5708 & 1.3333 & -1.2187 & 0.3071 & 0.3584 & -1.3547 & -0.2370 & -1.5820 & 2.1712 & 0.2203 & 1.9324 \\
\hline 2.5708 & 2.1768 & 1.3306 & -0.9567 & 0.2513 & 0.2653 & -0.9749 & -0.1979 & -1.2434 & 1.8447 & 0.2055 & 1.6002 \\
\hline 1.3333 & 1.3306 & 1.2195 & -0.4422 & 0.0877 & 0.1704 & -0.0118 & -0.1655 & -0.4436 & 0.6753 & 0.1248 & 0.4493 \\
\hline-1.2187 & -0.9567 & -0.4422 & 2.6963 & -0.6476 & 0.2129 & -0.2859 & 0.0724 & 0.6286 & -4.9689 & -0.0832 & -4.9069 \\
\hline 0.3071 & 0.2513 & 0.0877 & -0.6476 & 0.3671 & 0.0608 & 0.7858 & -0.0168 & 0.3159 & 2.3188 & 0.0127 & 2.2968 \\
\hline 0.3584 & 0.2653 & 0.1704 & 0.2129 & 0.0608 & 0.7499 & 2.5843 & -0.0465 & 1.1816 & -0.2306 & -0.0898 & -0.2786 \\
\hline-1.3547 & -0.9749 & -0.0118 & -0.2859 & 0.7858 & 2.5843 & 43.2366 & 0.3750 & 16.7087 & 3.5172 & -0.3428 & 3.2939 \\
\hline-0.2370 & -0.1979 & -0.1655 & 0.0724 & -0.0168 & -0.0465 & 0.3750 & 0.0576 & 0.2487 & -0.0746 & -0.0111 & -0.0451 \\
\hline-1.5820 & -1.2434 & -0.4436 & 0.6286 & 0.3159 & 1.1816 & 16.7087 & 0.2487 & 9.1239 & 1.1754 & -0.4729 & 1.2091 \\
\hline 2.1712 & 1.8447 & 0.6753 & -4.9689 & 2.3188 & -0.2306 & 3.5172 & -0.0746 & 1.1754 & 15.7782 & 0.1693 & 15.6395 \\
\hline 0.2203 & 0.2055 & 0.1248 & -0.0832 & 0.0127 & -0.0898 & -0.3428 & -0.0111 & -0.4729 & 0.1693 & 0.0849 & 0.1427 \\
\hline 1.9324 & 1.6002 & 0.4493 & -4.9069 & 2.2968 & -0.2786 & 3.2939 & -0.0451 & 1.2091 & 15.6395 & 0.1427 & 15.5470 \\
\hline
\end{tabular}
em relação aos anos de 2001, 2002 e 2003, confor-

\begin{tabular}{|c|c|c|c|c|c|c|c|c|c|c|c|}
\hline 1.0000 & 0.9533 & 0.6605 & -0.4061 & 0.2773 & 0.2264 & -0.1127 & -0.5402 & -0.2866 & 0.2991 & 0.4137 & 0.2681 \\
\hline 0.9533 & 1.0000 & 0.8167 & -0.3949 & 0.2812 & 0.2077 & -0.1005 & -0.5588 & -0.2790 & 0.3148 & 0.4780 & 0.2751 \\
\hline 0.6605 & 0.8167 & 1.0000 & -0.2439 & 0.1311 & 0.1782 & -0.0016 & -0.6244 & -0.1330 & 0.1539 & 0.3879 & 0.1032 \\
\hline-0.4061 & -0.3949 & -0.2439 & 1.0000 & -0.6510 & 0.1497 & -0.0265 & 0.1836 & 0.1267 & -0.7618 & -0.1739 & -0.7579 \\
\hline 0.2773 & 0.2812 & 0.1311 & -0.6510 & 1.0000 & 0.1159 & 0.1972 & -0.1156 & 0.1726 & 0.9635 & 0.0720 & 0.9615 \\
\hline 0.2264 & 0.2077 & 0.1782 & 0.1497 & 0.1159 & 1.0000 & 0.4539 & -0.2236 & 0.4517 & -0.0670 & -0.3559 & -0.0816 \\
\hline-0.1127 & -0.1005 & -0.0016 & -0.0265 & 0.1972 & 0.4539 & 1.0000 & 0.2376 & 0.8413 & 0.1347 & -0.1789 & 0.1270 \\
\hline-0.5402 & -0.5588 & -0.6244 & 0.1836 & -0.1156 & -0.2236 & 0.2376 & 1.0000 & 0.3430 & -0.0782 & -0.1581 & -0.0476 \\
\hline
\end{tabular}
me valores apresentados pelo software Matalab.

Análise feita com os três anos em conjunto: 
Continuação

\begin{tabular}{|l|l|l|l|l|l|l|l|l|l|l|l|}
\hline \multicolumn{1}{|c|}{ MATRIZ CORRELAÇÃO } \\
\hline-0.2866 & -0.2790 & -0.1330 & 0.1267 & 0.1726 & 0.4517 & 0.8413 & 0.3430 & 1.0000 & 0.0980 & -0.5373 & 0.1015 \\
\hline 0.2991 & 0.3148 & 0.1539 & -0.7618 & 0.9635 & -0.0670 & 0.1347 & -0.0782 & 0.0980 & 1.0000 & 0.1463 & 0.9986 \\
\hline 0.4137 & 0.4780 & 0.3879 & -0.1739 & 0.0720 & -0.3559 & -0.1789 & -0.1581 & -0.5373 & 0.1463 & 1.0000 & 0.1242 \\
\hline 0.2681 & 0.2751 & 0.1032 & -0.7579 & 0.9615 & -0.0816 & 0.1270 & -0.0476 & 0.1015 & 0.9986 & 0.1242 & 1.0000 \\
\hline
\end{tabular}

\begin{tabular}{|c|c|c|c|c|c|c|c|c|c|c|c|}
\hline 51.6469 & 32.7139 & 5.9910 & 2.1006 & 0.8295 & 0.6114 & 0.3963 & 0.0502 & 0.0196 & 0.0122 & 0.0064 & 0.0007 \\
\hline
\end{tabular}

SETE AUTOVALORES MENORES QUE 0,7 => SETE VARIÁVEIS A SEREM DESCARTADAS.

\begin{tabular}{|c|c|c|c|c|c|c|c|c|c|c|c|c|}
\hline V1 & -0.0211 & 0.1284 & -0.6469 & -0.2249 & 0.0139 & -0.4241 & 0.3451 & 0.3650 & -0.2072 & 0.1558 & -0.1191 & -0.0159 \\
\hline V2 & -0.0143 & 0.1053 & -0.5310 & -0.1932 & 0.0452 & 0.1260 & 0.0675 & -0.6038 & 0.4060 & -0.2398 & 0.2440 & 0.0226 \\
\hline V3 & 0.0002 & 0.0382 & -0.3441 & -0.1601 & -0.0790 & 0.7718 & -0.2976 & 0.2267 & -0.1805 & 0.2187 & -0.1291 & 0.1244 \\
\hline V4 & -0.0361 & -0.2259 & 0.1179 & -0.3115 & 0.8903 & 0.1099 & 0.1314 & 0.0561 & 0.0623 & 0.0503 & -0.0697 & 0.0198 \\
\hline V5 & 0.0324 & 0.0931 & 0.0162 & -0.0369 & 0.1016 & -0.0415 & -0.1362 & 0.1726 & -0.2063 & 0.1554 & 0.9273 & 0.0402 \\
\hline V6 & 0.0517 & -0.0313 & -0.1147 & -0.2301 & 0.1085 & -0.4130 & -0.8325 & -0.1310 & -0.1141 & -0.0289 & -0.1546 & -0.0005 \\
\hline V7 & 0.8932 & -0.2214 & -0.1804 & 0.3256 & 0.1114 & 0.0047 & 0.0034 & 0.0170 & 0.0345 & 0.0234 & -0.0042 & 0.0106 \\
\hline V8 & 0.0079 & -0.0081 & 0.0536 & 0.0176 & -0.0022 & -0.0415 & 0.1368 & -0.5893 & -0.3453 & 0.7107 & -0.0679 & 0.0098 \\
\hline V9 & 0.3635 & -0.1125 & 0.2832 & -0.7864 & -0.3384 & 0.0223 & 0.1616 & -0.0276 & -0.0702 & -0.0919 & 0.0300 & -0.0204 \\
\hline V10 & 0.1814 & 0.6541 & 0.0948 & -0.0362 & 0.1477 & 0.0952 & -0.0387 & 0.0134 & 0.0258 & 0.0396 & -0.0658 & -0.6999 \\
\hline V11 & -0.0084 & 0.0126 & -0.0555 & 0.0933 & 0.1134 & 0.1014 & 0.1081 & -0.2280 & -0.7576 & -0.5708 & -0.0173 & -0.0340 \\
\hline V12 & 0.1770 & 0.6485 & 0.1615 & -0.0194 & 0.1236 & -0.0506 & 0.0313 & -0.0145 & 0.0155 & -0.0390 & -0.1037 & 0.7001 \\
\hline
\end{tabular}

VARIÁVEIS A SEREM DESCARTADAS: $2,3,5,6,8,11$, 12. PROPORÇÃO DE VARIÂNCIA EXPLICADA PELOS AUTOVALORES DA MATRIZ COVARIÂNCIA

\begin{tabular}{|c|c|c|c|}
\hline ORDEM & AUTOVALORES & VAR. EXPL. (EM \%) & VAR. EXPL. ACUM (\%) \\
\hline 1 & 51.6469 & 54.72 & 54.72 \\
\hline 2 & 32.7139 & 34.66 & 89.39 \\
\hline 3 & 5.9910 & 6.35 & 95.73 \\
\hline 4 & 2.1006 & 2.23 & 97.96 \\
\hline 5 & 0.8295 & 0.88 & 98.84 \\
\hline 6 & 0.6114 & 0.65 & 99.49 \\
\hline 7 & 0.3963 & 0.42 & 99.91 \\
\hline 8 & 0.0502 & 0.05 & 99.96 \\
\hline 9 & 0.0196 & 0.02 & 99.98 \\
\hline 10 & 0.0122 & 0.01 & 99.99 \\
\hline
\end{tabular}




\begin{tabular}{|c|c|c|c|}
\hline \multicolumn{4}{|c|}{ Continuação } \\
\hline ORDEM & AUTOVALORES & VAR. EXPL. (EM \%) & VAR. EXPL. ACUM (\%) \\
\hline 11 & 0.0064 & 0.01 & 100.00 \\
\hline 12 & 0.0007 & 0.00 & 100.00 \\
\hline
\end{tabular}

Após o descarte, restaram 5 variáveis. A análise é feita novamente com essas variáveis.

\begin{tabular}{|l|l|l|l|l|}
\hline \multicolumn{5}{|l|}{ MATRIZ COVARIÂNCIA } \\
\hline 3.3408 & -1.2187 & -1.3547 & -1.5820 & 2.1712 \\
\hline-1.2187 & 2.6963 & -0.2859 & 0.6286 & -4.9689 \\
\hline-1.3547 & -0.2859 & 43.2366 & 16.7087 & 3.5172 \\
\hline-1.5820 & 0.6286 & 16.7087 & 9.1239 & 1.1754 \\
\hline 2.1712 & -4.9689 & 3.5172 & 1.1754 & 15.7782 \\
\hline
\end{tabular}

\begin{tabular}{|l|l|l|l|l|}
\hline \multicolumn{5}{|l|}{ MATRIZ CORRELAÇÃO } \\
\hline 1.0000 & -0.4061 & -0.1127 & -0.2866 & 0.2991 \\
\hline-0.4061 & 1.0000 & -0.0265 & 0.1267 & -0.7618 \\
\hline-0.1127 & -0.0265 & 1.0000 & 0.8413 & 0.1347 \\
\hline-0.2866 & 0.1267 & 0.8413 & 1.0000 & 0.0980 \\
\hline 0.2991 & -0.7618 & 0.1347 & 0.0980 & 1.0000 \\
\hline
\end{tabular}

Tabela 3 - Componentes principais com autovalores da matriz covariância

\begin{tabular}{c|c}
\hline Componentes principais & \\
\hline CP 1 & 51,6469 \\
\hline CP 2 & 32,7139 \\
\hline CP 3 & 5,9910 \\
\hline CP 4 & 2,1006 \\
\hline CP 5 & 0,8295 \\
\hline CP 6 & 0,6114 \\
\hline CP 7 & 0,3963 \\
\hline CP 8 & 0,0502 \\
\hline CP 9 & 0,0196 \\
\hline CP 10 & 0,0122 \\
\hline CP 11 & 0,0064 \\
\hline CP 12 & 0,0007
\end{tabular}

Fonte: Elaborada pelos autores

Na Tabela 3, faz-se a relação entre as componentes principais e os autovalores da matriz covariância dos 3 anos analisados.
Com base no cálculo de cada autovetor correspondente aos menores autovalores, pôde-se identificar quais as variáveis com maior coeficiente. Dessa forma, foi possível fazer o descarte, utilizando-se a aplicação da análise das componentes principais. O objetivo foi descartar as variáveis não representativas na análise dos anos 2001, 2002 e 2003.

As variáveis descartadas estão evidenciadas na Tabela 4 a qual demonstra quais foram as variáveis que não contribuíram na análise.

Essas variáveis foram descartadas, portanto, não contribuíram para explicar a variabilidade dos dados, ou seja, essas 7 variáveis em conjunto detêm $1,16 \%$ de grau de importância na análise das demonstrações contábeis, segundo a metodologia da 'ACP' demonstrada na Tabela 3. Com as variáveis restantes, que totalizam 5 das 12 estudadas inicialmente, foram observadas e aplicadas a mesma metodologia da 'ACP' para identificar qual o grau de importância de cada índice de forma individual.

Após o descarte, restaram apenas 5 variáveis nas quais foi novamente aplicada a análise das componentes principais, utilizando-se para entrada de dados as 30 observações, com as 5 variáveis restantes, representadas pelo índice de liquidez geral; giro do ativo; participação de capital de terceiros; imobilização do patrimônio líquido e capital circulante líquido, por meio de uma matriz $30 \times 5$ no Software Matlab.

O objetivo da análise foi identificar os autovetores da matriz covariância para verificar a ordem de importância de cada índice na explicação da variabilidade do sistema.

A componente principal CP1 mais relevante e que mais contribui para explicar o sistema é a variável 7; seguida da CP2, representada pela variável 10; a CP3, representada pela variável 1; na seqüência a CP4, representada pela variável 9; e finalizando a CP5, representada pela variável 4 .

Faz-se necessário identificar as variáveis descritas neste estudo, conforme a representatividade para explicar a variabilidade total dos dados representados pelos seguintes índices: Variável 7 - Participação de capitais de terceiros; Variável 10 - Capital circulante líquido; Variável 1 - Liquidez geral; Variável 9 - Imobilização do patrimônio líquido; Variável 4 - Giro do ativo. Nessa ordem, pôde-se calcular a variabilidade explicada para cada uma das variáveis, conforme a Tabela 6. 
Tabela 4 - Variáveis descartadas pela ACP

\begin{tabular}{c|c|l}
\hline Relação das variáveis descartadas & & \\
\hline Variável & 2 & liquidez corrente \\
\hline Variável & 3 & liquidez seca \\
\hline Variável & 5 & rentabilidade do ativo \\
\hline Variável & 6 & rentabilidade do patrimônio líquido \\
\hline Variável & 8 & composição das exigibilidades \\
\hline Variável & 11 & capital de giro \\
\hline Variável & 12 & necessidade líquida de capital de giro \\
\hline
\end{tabular}

Fonte: Elaborada pelo autor.

Tabela 5 - Identificação do grau de importância das variáveis após aplicação da ACP

\begin{tabular}{c|c|c|c|c|c}
\hline Variáveis & CP1 & CP2 & CP3 & CP4 & CP5 \\
\hline Variável - 1 & -0.0339 & 0.1834 & $\underline{-0.7439}$ & 0.6404 & 0.0426 \\
\hline Variável - 4 & -0.0106 & -0.3244 & 0.1806 & 0.2425 & $\underline{0.8962}$ \\
\hline Variável - 7 & $\underline{0.9201}$ & -0.0725 & -0.2705 & -0.2519 & 0.1073 \\
\hline Variável - 9 & 0.3756 & -0.0735 & 0.5354 & $\underline{0.6838}$ & -0.3150 \\
\hline Variável - 10 & 0.1053 & $\underline{0.9222}$ & 0.2328 & -0.0073 & 0.2902 \\
\hline
\end{tabular}

Fonte: Elaborada pelo autor.

Tabela 6 - Variabilidade explicada em percentual pelas variáveis individuais e acumuladas

\begin{tabular}{c|c|c|c}
\hline Ordem & Autovalores & Var. Expl. (em \%) & Var. Expl. Acum (\%) \\
\hline Variável 7 & 51.6469 & $54.72 \%$ & $54.72 \%$ \\
\hline Variável 10 & 32.7139 & $34.66 \%$ & $89.39 \%$ \\
\hline Variável 1 & 5.9910 & $6.35 \%$ & $95.73 \%$ \\
\hline Variável 9 & 2.1006 & $2.23 \%$ & $97.96 \%$ \\
\hline Variável 4 & 0.8295 & $0.88 \%$ & $98.84 \%$
\end{tabular}

Fonte: Elaborada pelos autores.

Os resultados evidenciam que a variabilidade explicada pelas 5 variáveis chegou a 98,84, acarretando uma margem de erro de $1,16 \%$ no resultado final da pesquisa. Entretanto, ressalte-se que a variabilidade explicada pelas variáveis de forma individual apresentou a variável 7 com maior representatividade, com percentual de $54,72 \%$ do total; na seqüência, a variável 10 apresenta $34,66 \%$, seguida pelas variáveis 1,9 e 4, simultaneamente.

As 12 variáveis estudadas inicialmente evidenciam tendência para insolvência nas empresas em estudo, porém, por meio da análise das componentes principais, pode-se explicar a variabilidade com apenas 5 variáveis.

\section{CONSIDERAÇÕES FINAIS}

Apresenta-se, aqui, uma síntese dos resultados deste estudo, buscando fazer a integração das seções anteriores. Para isso, é mister fazer a relação entre os dados coletados na pesquisa com a bibliografia apresentada, que vem ao encontro do objetivo, conforme proposto no início deste artigo.

Os resultados apresentados revelam que 0 objetivo geral deste trabalho foi alcançado, que consistiu em examinar a situação econômico-financeira das empresas em processo de concordata, a fim de se ressaltar a possibilidade de a análise das 
demonstrações contábeis evidenciar tendência de processo de concordata.

Foi realizado um estudo sobre o grupo de índices utilizados na análise das demonstrações contábeis que, na revisão da literatura, foram apresentados sob o ponto de vista de diversos autores e, por meio da exposição de suas idéias, possibilitaram apresentar a fundamentação teórica para sustentação deste trabalho, confrontando a teoria com a prática.

Por meio da análise das demonstrações contábeis, foi possível verificar a contribuição de cada índice selecionado para este estudo, com o intuito de identificar o grau de importância para uma possível evidenciação de estado de insolvência nas empresas.

Buscou-se identificar entre os índices selecionados, quais os mais relevantes para o usuário da análise de balanço em relação ao grau de importância na geração de informações, descartando-se os índices que não contribuem para explicar a variabilidade dos dados, dessa forma não gerando informações irrelevantes pela análise das demonstrações contábeis.

Após o tratamento estatístico dos dados feito por meio da análise das componentes principais 'ACP', foi possível identificar entre as 12 variáveis quais índices são mais relevantes para explicar a variabilidade dos dados.

Foi possível identificar os 5 índices, aqui chamados de variáveis, com maior relevância na análise das demonstrações contábeis com o objetivo de verificar a tendência para a insolvência. $\mathrm{Na}$ ordem de importância, têm-se: índice de participação de capitais de terceiros; índice de capital circulante líquido; índice de liquidez geral; índice de imobilização do patrimônio líquido e o índice de giro do ativo, respectivamente.

Diante desse contexto, os resultados apontam que é possível utilizar apenas 5 das 12 variáveis estudadas inicialmente, com fins específicos de analisar se tais empresas têm tendência para insolvência e chegar-se à conclusão de que, quando utilizadas essas 5 variáveis na análise das demonstrações contábeis, e os índices encontrados evidenciarem uma variabilidade decrescente no resultado da análise, a empresa analisada poderá estar se direcionando para processo de insolvência com base nos índices selecionados.

Conclui-se, dessa forma, que os 5 índices evidenciados pela 'ACP' nessa pesquisa podem ser utilizados como direcionadores de concordata, em vez de utilizar os 12 inicialmente propostos, considerando-se as empresas pesquisadas.

\section{REFERÊNCIAS BIBLIOGRÁFICAS}

ASSAF NETO, Alexandre. Finanças corporativas e valor. São Paulo: Atlas, 2003.

Atlas, 2002.

Estrutura e análise de balanços. $7^{\mathrm{a}}$ ed. São Paulo:

BODIE, Zvi; MERTON, Robert C.. Finance. Prentice-Hall. Simon \& Company, 1998.

BRIGHAM, Eugene F.; GAPENSKI, Louis C.; EHRHARDT, Michae C.. Administração Financeira: Teoria e Prática. São Paulo: Atlas, 2001.

DAMODARAN, Aswath. Finanças corporativas aplicadas: manual do usuário. Tradução Jorge Ritter. Porto Alegre: Bookman, 2002.

GARRISON, Ray H.; NORREN, Eric W.. Contabilidade gerencial. 9. ${ }^{a}$ ed. Rio de Janeiro: LTC, 2001.

GIL, Antonio Carlos. Como elaborar Projetos de Pesquisa. $4^{\mathrm{a}}$ ed. São Paulo: Atlas, 2002.

GITMAN, Lawrence J; MADURA, Jeff. Administração financeira: uma abordagem gerencial. São Paulo: Pearson, 2003.
GROPPELLI, A.A.; NIKBAKHT, Ehsan. Administração financeira. 3. $^{a}$ ed. São Paulo: Saraiva, 1999.

HELFERT, Erich A.. Técnicas de análise financeira. Porto Alegre: Bookman, 2000.

HOUSTON, Joel F.; BRIGHAM, Eugene F.. Fundamentos da moderna administração financeira. Porto Alegre: Campus, 1999.

IUDíCIBUS, Sérgio de. Análise de Balanços. 7. ${ }^{a}$ ed. São Paulo: Atlas, 1998.

JOHNSON, Richard A.; WICHERN, Dean W.. Applied multivariate statistical analysis. 4. ${ }^{a}$ ed. New Jersey: Prentice Hall, 1998.

KAZMIER, Leonardo J.. Estatística aplicada à economia e administração. São Paulo: Makrons Book, 1982.

LANDIM, P.M.B.. Análise estatística de dados geológicos multivariados. DGA, IGCE, UNESP/Rio Claro, Lab. Geomatemática, Texto Didático 03, 96 p. 2000. Disponível em <http:/www.rc.unesp. Br/igce/aplicada/textodi.html>.Acesso em: 17 dez. 2004.

MARDIA, K. V.; KENT, J. P.; BIBBY, J. M.. Multivariane Analysis. London: Academic Press, 1979, 175-178. 
MARION, José Carlos. Análise das demonstrações contábeis: contabilidade empresarial. 2. ${ }^{a}$ ed. São Paulo: Atlas, 2002.

MATARAZZO, Dante C.. Análise financeira de balanços: aborgadem básica. 2. ${ }^{a}$ ed. São Paulo: Atlas, 1985.

Atlas, 2003.

Análise financeira de balanços. $6 .^{\mathrm{a}}$ ed. São Paulo:

MINTZBERG, H. et al.. The strategy process. Englewwod Cliffs, Hew Jersey: Prentice Hall, 1988.

OLINQUEVITCH, José Leônidas; SANTI FILHO, Armando de. Análise de balanços para controle gerencial. $4 .^{a}$ ed. São Paulo: Atlas, 2004.

PADOVEZE, Clóvis L.. Controladoria estratégica e operacional. São Paulo:Thomson, 2003.

RICHARDSON, Roberto Jarry. Pesquisa Social: métodos e técnicas. 2. ${ }^{a}$ ed. São Paulo: Atlas, 1989.

ROSS, Stephen A.; WESTERFIEL, Randolph W.; JAFFE, Jeffrey F. Corporate finance. The McGraw-Hill Companies, 2002.
SANTOS, Vilmar Pereira dos. Manual de diagnóstico e reestruturação financeira de empresas. $2^{a}$ ed. São Paulo: Atlas, 2000.

SERASA - Solução em Informação. Disponível em: <http://www. serasa.com.br/indices/ idconcordata_04.htm>. Acesso em: 20 abr. 2004.

SILVA, José Pereira da. Analise financeira das empresas. $5^{\mathrm{a}}$ ed. São Paulo: Atlas, 2001.

Paulo: Atlas, 2003

Gestão e análise de risco de crédito. $4^{\mathrm{a}}$ ed. São

SCHRICKEL, Wolfgang Kurt. Demonstrações Financeiras: abrindo a caixa-preta. 2. ${ }^{a}$ ed. São Paulo: Atlas, 1999.

WESTON, J. Fred; BRIGHAM, Eugene F.. Essentials of managerial finance. The Dryden Press, 2000.

WRIGHT, Peter; KROLL, Mark J.; PARNELL, John. Administração estratégica. São Paulo: Atlas, 2000.

\section{Endereço dos autores:}

Unicentro

Rua Presidente Zacarias, 875

Guarapuava - PR

85.015-430
FURB

Rua Antonio da Veiga, 140 - Victor Konder

Blumenau - SC

89.010-971 